\title{
Infrared-Induced Rotamerization of Oxalic Acid Monomer in Argon Matrix
}

\author{
Ermelinda M. S. Maçôas and Rui Fausto* \\ Department of Chemistry-CQC, University of Coimbra, P-3049 Coimbra, Portugal \\ Mika Pettersson, Leonid Khriachtchev, and Markku Räsänen \\ Laboratory of Physical Chemistry, University of Helsinki, P.O. Box 55 (A.I. Virtasen aukio 1), \\ FIN-00014 Helsinki, Finland
}

Received: February 17, 2000; In Final Form: April 27, 2000

\begin{abstract}
Infrared-induced conformational isomerization of oxalic acid monomer isolated in an argon matrix at $7.5 \mathrm{~K}$ was studied by infrared spectroscopy. For the first time, three conformational states of this molecule were identified experimentally and their vibrational spectra are assigned. In good agreement with density functional theory predictions, all the observed conformers exhibit a trans $\mathrm{O}=\mathrm{C}-\mathrm{C}=\mathrm{O}$ axis, differing in the relative conformation of their $\mathrm{O}-\mathrm{C}-\mathrm{O}-\mathrm{H}$ axes. In the most stable conformer (belonging to the $C_{2 h}$ symmetry point group), two intramolecular $\mathrm{OH} \cdots \mathrm{O}=$ hydrogen bonds are present. The second $\left(C_{s}\right)$ most stable conformer shows a single $\mathrm{OH} \cdots \mathrm{O}=$ bond, and the third one $\left(C_{2 h}\right)$ does not exhibit any intramolecular hydrogen bond. Using narrowband tunable irradiation in the near-infrared region it was possible to promote very efficiently conformer interconversions, which was followed spectroscopically.
\end{abstract}

\section{Introduction}

Oxalic acid (ethanedioic acid; $\mathrm{C}_{2} \mathrm{H}_{2} \mathrm{O}_{4}$ ) is the smallest member in the series of aliphatic dicarboxylic acids. At room temperature, it exists in two crystalline varieties, the stable orthorhombic $\alpha$-phase and the metastable monoclinic $\beta$-phase. ${ }^{1,2}$ In both crystalline phases, where extensive intermolecular hydrogen bonding occurs, individual molecules were found to be exclusively in a conformation where the $\mathrm{O}-\mathrm{C}-\mathrm{C}-\mathrm{O}$ dihedral angle is $180^{\circ}$, that is, the two carbonyl groups are trans to each other, and the two $\mathrm{H}-\mathrm{O}-\mathrm{C}-\mathrm{C}$ dihedral angles assume a trans configuration (conformer $\mathbf{t T t}^{\dagger}$, in Figure 1) ${ }^{1,2}$ However, in both gaseous phase and in inert gas matrices at low temperatures, monomeric oxalic acid has been found to exist predominantly in a different conformation, where the two $\mathrm{H}-\mathrm{O}-\mathrm{C}-\mathrm{C}$ dihedrals adopt the cis configuration and are involved in intramolecular hydrogen bonding (form $\mathbf{c T c}$ ).$^{3-5}$

High-level ab initio and density functional theory (DFT) calculations on monomeric oxalic acid have also been reported previously. ${ }^{6-8}$ In general, the highest-level theoretical calculations predict the existence of at least five conformers of oxalic acid. In good agreement with the available experimental results, ${ }^{3-5}$ the calculations systematically predict conformer cTc as corresponding to the most stable form. In an earlier matrix isolation infrared (IR) spectroscopic study, some evidence could be found pointing to the existence of more than one conformer of oxalic acid trapped in the matrices. ${ }^{4}$ However, only the second most stable conformer predicted by the calculations (form cTt, in Figure 1) could be unequivocally identified experimentally. ${ }^{3}$ A recent Stark-modulated free jet microwave spectroscopic study ${ }^{8}$ has confirmed the structure of this conformer. The other

* Author to whom all correspondence should be addressed.

$\dagger$ The nomenclature here adopted is the same used in the previous experimental paper on oxalic acid; ${ }^{3}$ an uppercase letter designates the $\mathrm{O}-\mathrm{C}-$ $\mathrm{C}-\mathrm{O}$ dihedral angle $(\varphi ; \mathrm{C}$, cis; T, trans; $\mathrm{G}$, gauche $)$, and the first and last lowercase letters designate the $\mathrm{HOCC}\left(\tau_{1}\right)$ and $\mathrm{CCOH}\left(\tau_{2}\right)$ dihedral angles, respectively.

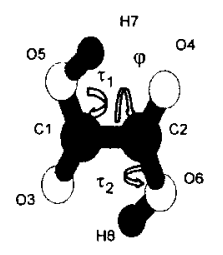

cTe (0.0)

$\mathrm{C}_{2 h}$

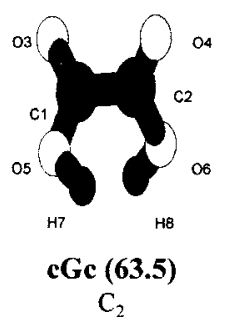

$\mathrm{C}_{2}$

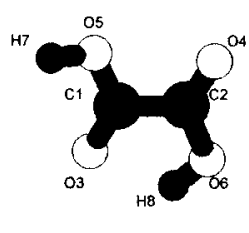

cTt (10.1)

$\mathrm{C}_{\mathrm{S}}$

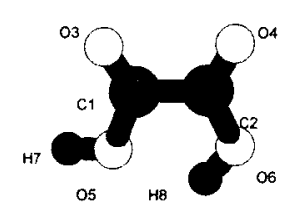

$\operatorname{cCt}(22.9)$

$\mathrm{C}_{\mathrm{S}}$

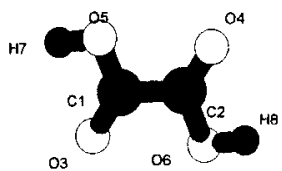

tTt (15.1)

$\mathrm{C}_{2 \mathrm{~h}}$

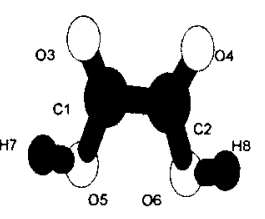

tCt (16.7)

$\mathrm{C}_{2 \mathrm{v}}$
Figure 1. B3LYP/6-31G**-calculated conformers of monomeric oxalic acid. $^{7}$ The difference in energy $\left(\mathrm{kJmol}^{-1}\right)$, including zero-point vibrational energy-corrected relative conformational energies to the most stable form, ${ }^{7}$ are given in parentheses. Form cGc was found to correspond to an energy maximum both at ha HF/6-31G**2 and MP2/ $6-311++\mathrm{G}^{* * 8}$ (see text).

theoretically predicted conformers of oxalic acid have not been observed until now, though at least the third- and fourth-lowestenergy conformers (forms $\mathbf{t} \mathbf{T t}$ and $\mathbf{t C t}$ ) were calculated to have relatively accessible excess energies to the conformational ground state. ${ }^{7,8}$ The B3LYP/6-31G**7 and MP2/6-31G**3 calculations provided identical results predicting the existence of six conformers, all but the highest-energy form (cGc in Figure 1) being planar. However, a more recent study carried out at the MP2/6-311++ $\mathrm{G}^{* *}$ level of theory, where energy profiles associated with internal rotation around the $\mathrm{C}-\mathrm{C}$ and $\mathrm{C}-\mathrm{O}$ bonds were calculated, indicates that $\mathbf{c G c}$ does not correspond 
to a true energy minimum, whereas the $\mathbf{t T t}$, $\mathbf{t C t}$, and $\mathbf{c C t}$ forms are slightly distorted from planarity. ${ }^{8}$

Identification of conformer cTt was achieved by observation of IR- and ultraviolet (UV)-induced conformational processes for oxalic acid isolated in noble gas matrices at low temperature, followed by IR spectroscopy. ${ }^{3} \mathrm{~A}$ Xe arc lamp with a narrowband filter $(\max 270 \mathrm{~nm}$, full width at half-maximum $30 \mathrm{~nm}$, corresponding to the $\pi^{* \leftarrow n}$ transition ${ }^{9}$ ) was used for UV irradiation, which was found to induce $\mathbf{c} \mathbf{T} \mathbf{c} \rightarrow \mathbf{c} \mathbf{T t}$ isomerization, accompanied by partial decomposition of oxalic acid monomers. IR irradiation was carried out using the globar of the spectrometer either without filter or with a low-pass filter (transmitting ca. $80 \%$ between 2000 and $600 \mathrm{~cm}^{-1}$ ). Irradiation above 2000 $\mathrm{cm}^{-1}$ was found to be active at initiating the reverse process $(\mathbf{c T t} \rightarrow \mathbf{c T c} \text { isomerization })^{3}$

It has repeatedly been reported for other carboxylic acid monomers that selective excitation of the $\mathrm{OH}$ stretching vibrations are of great utility to study conformational isomerization processes in this type of compound. ${ }^{10-12}$ Furthermore, contrary to UV irradiation, IR irradiation does not usually lead to decomposition of the matrix-isolated molecules. Because the IR irradiation carried out in the previous study on oxalic acid was not selective, we decided to submit this compound to a new investigation, where selective narrowband and tunable IR irradiation was used, to better characterize the observed isomerization processes and, in particular, to search for other conformational species.

\section{Experimental and Computational Details}

The matrix samples were prepared by continuously flushing a Teflon U-tube containing oxalic acid (Aldrich, 99+\%), heated to $100{ }^{\circ} \mathrm{C}$, with high-purity argon $(>99.995 \%)$. The gaseous mixture was deposited onto a cooled CsI window in a closecycle helium cryostat (APD, DE202A) at 7.5 K. The IR spectra $\left(4000-450 \mathrm{~cm}^{-1}\right)$ were measured with a Nicolet SX-60 Fourier transform IR spectrometer equipped with a liquid-nitrogencooled mercury-cadmium-telluride detector and a $\mathrm{KBr}$ beam splitter, with spectral resolutions of 0.25 or $1.0 \mathrm{~cm}^{-1}$. Typically 200 interferograms were coadded. In our samples, monomeric species were almost exclusively formed, which was achieved by choosing an appropriate temperature of the substance container and optimizing the matrix gas flow rate.

To promote conformational interconversions, tuneable pulsed IR irradiation was used, as provided by the idler beam of an optical parametric oscillator (OPO Sunlite, Continuum). The pulse duration of the IR irradiation was ca. $5 \mathrm{~ns}$ with a line width of $\sim 0.1 \mathrm{~cm}^{-1}$. The absolute accuracy of the IR radiation was established with an accuracy better than $1 \mathrm{~cm}^{-1}$ by a Burleigh WA-4500 wavemeter used to control the OPO signal radiation wavelength.

The DFT calculations were performed with the Becke's threeparameter hybrid method using the Lee-Yang-Parr's correlation functional ${ }^{13,14}$ and the $6-31 G^{* * 15}$ basis set. All the calculations were made with the GAUSSIAN 92/DFT package of programs, ${ }^{16}$ installed on a DEC ALPHA 7000 computer, at the Center of Informatics of the University of Coimbra.

The force constants (symmetry internal coordinates) to be used in the normal coordinate analysis were obtained from the DFT Cartesian harmonic force constants using the program TRANSFORMER. ${ }^{17}$ This program was also used to prepare the input data for the normal coordinate analysis programs used in this study (BUILD-G, and VIBRAT ${ }^{18}$ ). The calculated frequencies were then scaled by using a single scale factor $\left(0.9614^{8}\right)$ to obtain a better agreement with the experimental frequencies.
Although very simple, this scaling procedure preserves the potential energy distributions (PEDs) as they emerge from the DFT calculations, thus having an important advantage over the more elaborate force-field scaling procedures, which use more than one scale factor.

\section{Results and Discussion}

Conformer Interconversion. The high-level DFT calculations by Higgins et al. ${ }^{7}$ indicate that the energies of the secondto the fifth-lowest-energy forms of oxalic acid shall not exceed the energy of the most stable conformer by more than $25 \mathrm{~kJ}$ $\mathrm{mol}^{-1}$, whereas the highest-energy form (conformer cGc) has a predicted relative energy of $63.5 \mathrm{~kJ} \mathrm{~mol}^{-1}$. Thus, the relative populations of the different conformers of oxalic acid at the temperature used to prepare the matrix $(373 \mathrm{~K})$ are cTc:cTt: tTt:tCt:cCt:cGc $=$ 95.15:3.64:0.71:0.44:0.06: $<10^{-5}$ assuming a Boltzmann distribution. The MP2 results of Godfrey et al. ${ }^{8}$ do not differ qualitatively from the DFT data, although the relative energy differences between the conformers are somewhat smaller. In addition, as mentioned above, the MP2 study indicated that $\mathbf{c G c}$ does not correspond to a minimum in the potential energy surface. The potential energy profiles associated with the internal rotation around the $\mathrm{C}-\mathrm{C}$ bond for trans/trans or trans/cis arrangements of the carboxylic moieties calculated at the MP2 level of theory have revealed the following features: ${ }^{8}$ (a) Without taking into consideration zero-point vibrational energy corrections, the $\mathbf{t T t}, \mathbf{t C t}$, and $\mathbf{c C t}$ planar conformations should correspond to local maxima between two equivalent slightly distorted structures (the planar structures were calculated to be $0.26,1.02$, and $0.07 \mathrm{~kJ} \mathrm{~mol}^{-1}$ above the corresponding nonplanar minima, respectively). In the last case, however, the zero-point vibrational energy level of the true minimum energy conformation is $0.12 \mathrm{~kJ} \mathrm{~mol}^{-1}$ above the energy of the planar structure. Thus, the most probable structure falls at the symmetric planar position $(\mathbf{c C t})$. In addition, when zero-point vibrational energy is considered, the tTt planar structure becomes only $0.10 \mathrm{~kJ} \mathrm{~mol}^{-1}$ higher in energy than the corresponding distorted forms, and then the planar structure must also be the most probable geometry at temperatures higher than $13 \mathrm{~K}$. (b) The calculated energy barrier separating the distorted $\mathbf{t C t}$ forms from tTt is only ca. $1.6 \mathrm{~kJ} \mathrm{~mol}^{-1}$. Thus, at the temperature used in our study to prepare the sample (373 K), the available thermal energy can easily be used to overcome this barrier and, consequently, in the present context $\mathbf{t C t}$ is best regarded as vibrationally excited tTt rather than a separate species.

Taking into consideration the theoretical predictions, it can be expected that, in the gaseous phase at $373 \mathrm{~K}$, four conformers of monomeric oxalic acid exist (cTc, cTt, tTt, and cCt), although the highest-energy form $(\mathbf{c C t})$ should have a population smaller than $0.1 \%$. Assuming that gas-phase populations are trapped in the matrices, the presence of forms cTc, cTt, and tTt should in principle be detected in the vibrational spectra of matrix-isolated oxalic acid monomer.

The IR spectrum of a freshly prepared matrix of oxalic acid is dominated by intense bands due to the most stable cTc conformer. The assignments of these bands were discussed in detail elsewhere..$^{3,4}$

As expected, apart from the bands due to the conformational ground state (cTc), some minor bands ascribable to other conformers are also present in the spectrum. As mentioned in the Introduction, by irradiating the matrix in the $\mathrm{OH}$ stretching fundamental region, Nieminen et al. were able to observe conformational isomerization, the reaction product correspond- 
TABLE 1: Definition of Internal Symmetry Coordinates Used in Normal-Coordinate Analysis

\begin{tabular}{|c|c|c|c|c|c|c|}
\hline \multirow[b]{2}{*}{ coordinate } & \multicolumn{2}{|c|}{$\mathrm{cTc} / \mathrm{tTt}$} & \multicolumn{2}{|c|}{$\mathrm{cTt}$} & \multicolumn{2}{|c|}{ definition $^{a}$} \\
\hline & $\begin{array}{l}\text { approx. } \\
\text { desc. }\end{array}$ & $\begin{array}{l}\text { symmetry } \\
\quad\left(C_{2 h}\right)\end{array}$ & $\begin{array}{l}\text { approx. } \\
\text { desc. }\end{array}$ & $\begin{array}{l}\text { symmetry } \\
\left(C_{s}\right)\end{array}$ & $\mathrm{cTc} / \mathrm{tTt}$ & $\mathrm{cTt}$ \\
\hline$S_{1}$ & $v \mathrm{OH} \mathrm{s}$. & $A_{g}$ & $v \mathrm{OH}^{\prime}$ & $A^{\prime}$ & $v \mathrm{O}_{5} \mathrm{H}_{7}+v \mathrm{O}_{6} \mathrm{H}_{8}$ & $\nu \mathrm{O}_{6} \mathrm{H}_{8}$ \\
\hline$S_{2}$ & $v \mathrm{OH}$ & $B_{u}$ & $v \mathrm{OH}$ & $A^{\prime}$ & $v \mathrm{O}_{5} \mathrm{H}_{7}-v \mathrm{O}_{6} \mathrm{H}_{8}$ & $v \mathrm{O}_{5} \mathrm{H}_{7}$ \\
\hline$S_{3}$ & $v \mathrm{C}=\mathrm{O} \mathrm{s}$. & $A_{g}$ & $v \mathrm{C}=\mathrm{O}$ & $A^{\prime}$ & $v \mathrm{C}_{1}=\mathrm{O}_{3}+v \mathrm{C}_{2}=\mathrm{O}_{4}$ & $v \mathrm{C}_{2}=\mathrm{O}_{4}$ \\
\hline$S_{4}$ & $v \mathrm{C}=\mathrm{O}$ & $B_{u}$ & $v \mathrm{C}=\mathrm{O}^{\prime}$ & $A^{\prime}$ & $\nu \mathrm{C}_{1}=\mathrm{O}_{3}-\nu \mathrm{C}_{2}=\mathrm{O}_{4}$ & $\nu \mathrm{C}_{1}=\mathrm{O}_{3}$ \\
\hline$S_{5}$ & $v \mathrm{C}-\mathrm{O} \mathrm{s}$. & $A_{g}$ & $v \mathrm{C}-\mathrm{O} \mathrm{s}$ & $A^{\prime}$ & \multirow{2}{*}{\multicolumn{2}{|c|}{$\begin{aligned} & v \mathrm{C}_{1}-\mathrm{O}_{5}+\nu \mathrm{C}_{2}-\mathrm{O}_{6} \\
& \nu \mathrm{C}_{1}-\mathrm{O}_{5}-\nu \mathrm{C}_{2}-\mathrm{O}_{6}\end{aligned}$}} \\
\hline$S_{6}$ & $v \mathrm{C}-\mathrm{O}$ & $B_{u}$ & $v \mathrm{C}-\mathrm{O}$ & $A^{\prime}$ & & \\
\hline$S_{7}$ & $v \mathrm{C}-\mathrm{C}$ & $A_{g}$ & $v \mathrm{C}-\mathrm{C}$ & $A^{\prime}$ & \multicolumn{2}{|c|}{$v \mathrm{C}_{1}-\mathrm{C}_{2}$} \\
\hline$S_{8}$ & $\delta \mathrm{OCO} \mathrm{s}$. & $A_{g}^{\circ}$ & $\delta \mathrm{OCO}$ s. & $A^{\prime}$ & \multirow{4}{*}{\multicolumn{2}{|c|}{$\begin{aligned} 2 \delta \mathrm{O}_{5} \mathrm{C}_{1} \mathrm{O}_{3}-\delta \mathrm{C}_{2} \mathrm{C}_{1}= & \mathrm{O}_{3}-\delta \mathrm{C}_{2} \mathrm{C}_{1}-\mathrm{O}_{5}+2 \delta \mathrm{O}_{6} \mathrm{C}_{2} \mathrm{O}_{4}-\delta \mathrm{C}_{1} \mathrm{C}_{2}=\mathrm{O}_{4}-\delta \mathrm{C}_{1} \mathrm{C}_{2}-\mathrm{O}_{6} \\
2 \delta \mathrm{O}_{5} \mathrm{C}_{1} \mathrm{O}_{3}-\delta \mathrm{C}_{2} \mathrm{C}_{1}= & =\mathrm{O}_{3}-\delta \mathrm{C}_{2} \mathrm{C}_{1}-\mathrm{O}_{5}-2 \delta \mathrm{O}_{6} \mathrm{C}_{2} \mathrm{O}_{4}+\delta \mathrm{C}_{1} \mathrm{C}_{2}=\mathrm{O}_{4}+\delta \mathrm{C}_{1} \mathrm{C}_{2}-\mathrm{O}_{6} \\
\delta \mathrm{C}_{2} \mathrm{C}_{1}= & \mathrm{O}_{3}-\delta \mathrm{C}_{2} \mathrm{C}_{1}-\mathrm{O}_{5}+\delta \mathrm{C}_{1} \mathrm{C}_{2}=\mathrm{O}_{4}-\delta \mathrm{C}_{1} \mathrm{C}_{2}-\mathrm{O}_{6} \\
\delta \mathrm{C}_{2} \mathrm{C}_{1}= & =\mathrm{O}_{3}-\delta \mathrm{C}_{2} \mathrm{C}_{1}-\mathrm{O}_{5}-\delta \mathrm{C}_{1} \mathrm{C}_{2}=\mathrm{O}_{4}+\delta \mathrm{C}_{1} \mathrm{C}_{2}-\mathrm{O}_{6}\end{aligned}$}} \\
\hline$S_{9}$ & $\delta \mathrm{OCO}$ & $B_{u}^{\circ}$ & $\delta \mathrm{OCO}$ & $A^{\prime}$ & & \\
\hline$S_{10}$ & $\delta \mathrm{CC}=\mathrm{O} \mathrm{s}$. & $A_{g}$ & $\delta \mathrm{CC}=\mathrm{O} \mathrm{s}$. & $A^{\prime}$ & & \\
\hline$S_{11}$ & $\delta \mathrm{CC}=\mathrm{O}$ & $B_{u}$ & $\delta \mathrm{CC}=\mathrm{O}$ & $A^{\prime}$ & & \\
\hline$S_{12}$ & $\delta \mathrm{COH}$ s. & $A_{g}$ & $\delta \mathrm{COH} \mathrm{s.}$ & $A^{\prime}$ & \multicolumn{2}{|c|}{$\delta \mathrm{C}_{1} \mathrm{O}_{5} \mathrm{H}_{7}+\delta \mathrm{C}_{2} \mathrm{O}_{6} \mathrm{H}_{8}$} \\
\hline$S_{13}$ & $\delta \mathrm{COH}$ & $B_{u}$ & $\delta \mathrm{COH}$ & $A^{\prime}$ & \multicolumn{2}{|c|}{$\delta \mathrm{C}_{1} \mathrm{O}_{5} \mathrm{H}_{7}-\delta \mathrm{C}_{2} \mathrm{O}_{6} \mathrm{H}_{8}$} \\
\hline$S_{14}$ & $\gamma \mathrm{C}=\mathrm{O}$ & $A_{u}$ & $\gamma \mathrm{C}=\mathrm{O}$ & $A^{\prime \prime}$ & \multicolumn{2}{|c|}{$\gamma \mathrm{C}_{2}-\mathrm{C}_{1}\left(=\mathrm{O}_{3}\right)-\mathrm{O}_{5}+\gamma \mathrm{C}_{1}-\mathrm{C}_{2}\left(=\mathrm{O}_{4}\right)-\mathrm{O}_{6}$} \\
\hline$S_{15}$ & $\gamma \mathrm{C}=\mathrm{O} \mathrm{s}$. & $B_{g}$ & $\gamma \mathrm{C}=\mathrm{O} \mathrm{s}$. & $A^{\prime \prime}$ & \multirow{2}{*}{\multicolumn{2}{|c|}{$\begin{array}{r}\gamma \mathrm{C}_{2}-\mathrm{C}_{1}\left(=\mathrm{O}_{3}\right)-\mathrm{O}_{5}-\gamma \mathrm{C}_{1}-\mathrm{C}_{2}\left(=\mathrm{O}_{4}\right)-\mathrm{O}_{6} \\
\tau \mathrm{O}_{3}=\mathrm{C}_{1}-\mathrm{C}_{2}=\mathrm{O}_{4}\end{array}$}} \\
\hline$S_{16}$ & $\tau \mathrm{C}-\mathrm{C}$ & $A_{u}^{\circ}$ & $\tau \mathrm{C}-\mathrm{C}$ & $A^{\prime \prime}$ & & \\
\hline$S_{17}$ & $\tau \mathrm{C}-\mathrm{O}$ & $A_{u}$ & $\tau \mathrm{C}-\mathrm{O}$ & $A^{\prime \prime}$ & \multicolumn{2}{|c|}{$\tau \mathrm{O}_{3}=\mathrm{C}_{1}-\mathrm{O}_{5}-\mathrm{H}_{7}+\tau \mathrm{O}_{4}=\mathrm{C}_{2}-\mathrm{O}_{6}-\mathrm{H}_{8}$} \\
\hline$S_{18}$ & $\tau \mathrm{C}-\mathrm{O} \mathrm{s}$ & $B_{g}$ & $\tau \mathrm{C}-\mathrm{O} \mathrm{s}$ & $A^{\prime \prime}$ & \multicolumn{2}{|c|}{$\tau \mathrm{O}_{3}=\mathrm{C}_{1}-\mathrm{O}_{5}-\mathrm{H}_{7}-\tau \mathrm{O}_{4}=\mathrm{C}_{2}-\mathrm{O}_{6}-\mathrm{H}_{8}$} \\
\hline
\end{tabular}

${ }^{a}$ For atom numbering see Figure 1. $\nu$, stretching; $\delta$, bending; $\gamma$, rocking; $\tau$, torsion.

ing to the lowest-energy conformer, whereas this conformer behaved as the reactive species when the sample was irradiated in the UV region. ${ }^{3}$ The IR-reactive species was identified as corresponding to form cTt and a tentative assignment of the bands due to this conformer was also proposed in this previous study. However, the relatively low efficiency of the photoisomerization process did not allow the unequivocal assignment of all the observed features. In addition, a possible contribution from other conformers to the observed spectra could not be discarded.

In the present study, IR irradiation in the $6800-6700 \mathrm{~cm}^{-1}$ region was undertaken. In this spectral region, the $\mathrm{OH}$ stretching combination bands $\left(S_{1}+S_{2}\right.$; see Table 1 for definition of symmetry coordinates) or first overtones of the $\mathrm{OH}$ stretching vibrations of appropriate symmetry are expected to occur. Because the most stable conformer belongs to the $C_{2 h}$ symmetry point group, the first overtone of its $\mathrm{OH}$ stretching modes does not absorb in the IR radiation. Nevertheless, the $S_{1}+S_{2}$ combination band belongs to the $B_{u}$ symmetry species and then must correspond to the active vibration of the $\mathbf{c T c}$ conformer found at $\approx 6712 \mathrm{~cm}^{-1}$, which we have used to promote photochemical isomerization of this conformer to other forms. After 5 min of irradiation at this wave number, a noticeable reorganization of band intensities was observed. Figures 2 and 3 show difference spectra (irradiated sample-nonirradiated sample) in the $\mathrm{C}=\mathrm{O}$ and $\mathrm{OH}$ stretching regions obtained at different stages of irradiation. In Figure 3 the experimental features are compared with the DFT-calculated spectra.

In the $\mathrm{C}=\mathrm{O}$ stretching region, irradiation leads to an increase of the triplet around $1830 \mathrm{~cm}^{-1}$, and the doublets near 1780 and $1760 \mathrm{~cm}^{-1}$, whereas a decrease was observed in the case of the features at ca. $1810 \mathrm{~cm}^{-1}$ (see Figures 2 and 3). Comparison of the observed spectrum with the calculated spectra for the three most stable conformers (cTc, $\mathbf{c T t}$, and $\mathbf{t T t}$ ) clearly indicates that the irradiation leads to conversion of conformer cTc to both forms cTt and tTt. Thus, the irradiation is effective in promoting internal rotation about the $\mathrm{C}-\mathrm{O}$ bond.

It is known that when the carboxylic group assumes the cis arrangement $\left(\mathrm{C}-\mathrm{C}-\mathrm{O}-\mathrm{H}\right.$ dihedral angle equals $\left.0^{\circ}\right)$ the carbonyl stretching vibration occurs at a higher frequency than when it takes the trans geometry. This trend is essentially due to the fact that the $\left[\mathrm{O}=\mathrm{C}-\mathrm{O}-\mathrm{H} \leftrightarrow \mathrm{O}^{-}-\mathrm{C}=\mathrm{O}^{+}-\mathrm{H}\right]$ mesom-

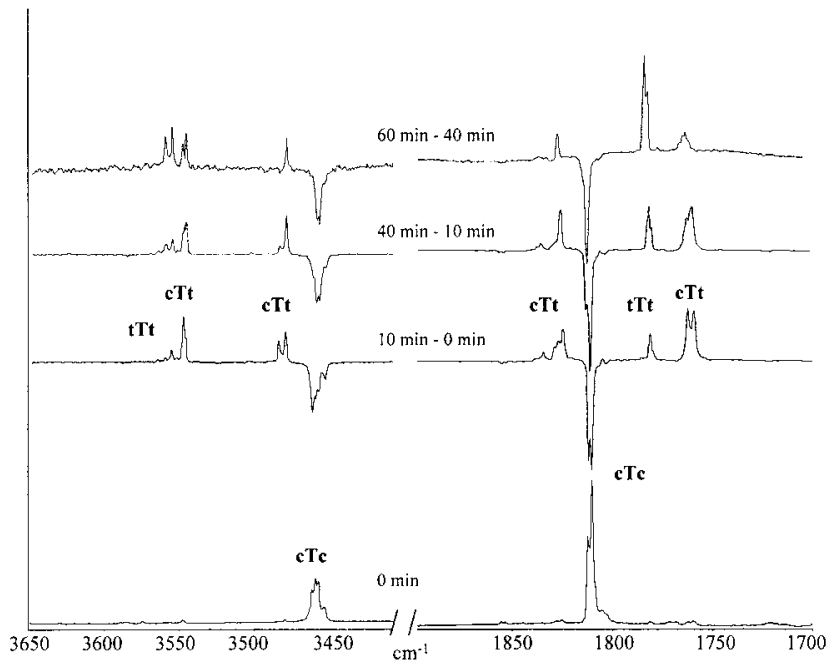

Figure 2. Observed spectrum of a nonirradiated sample of oxalic acid isolated in an Ar matrix $\left(3650-3400 \mathrm{~cm}^{-1}\right.$ and $1900-1700 \mathrm{~cm}^{-1}$ regions; intensities are shown in arbitrary units) and difference spectra obtained at different stages of irradiation at $6712 \mathrm{~cm}^{-1}$. It is clear from this figure that during the first stages of irradiation conformer cTt is the main product, whereas conformer $\mathbf{t T t}$ starts to become the dominant product at longer times of irradiation.

erism is more important in the cis than in the trans conformation of this group. ${ }^{19,20}$ Hence, the double-bond character of the carbonyl bond decreases and, consequently, the force constant associated with the $\mathrm{C}=\mathrm{O}$ stretching vibration reduces. On the other hand, intramolecular hydrogen bonding involving the carbonyl oxygen atom as acceptor also leads to a red shift in the frequency of the carbonyl stretching mode.

In the cTt conformer, the cis carboxylic group is not involved in hydrogen bonding and its carbonyl stretching mode absorbs near $1830 \mathrm{~cm}^{-1}$, whereas the hydrogen-bonded trans carboxylic group gives rise to the doublet occurring at a considerably lower frequency (ca. $1760 \mathrm{~cm}^{-1}$ ). In conformer cTc, both carbonyl groups adopt the cis arrangement but they also participate in intramolecular hydrogen bonding. Thus, in this conformer, the effects of carboxylic group conformation and intramolecular hydrogen bonding compensate partially each other. Consequently, the IR active carbonyl stretching mode ( $B_{u}$ symmetry) is expected to occur at a frequency between those of the modes 


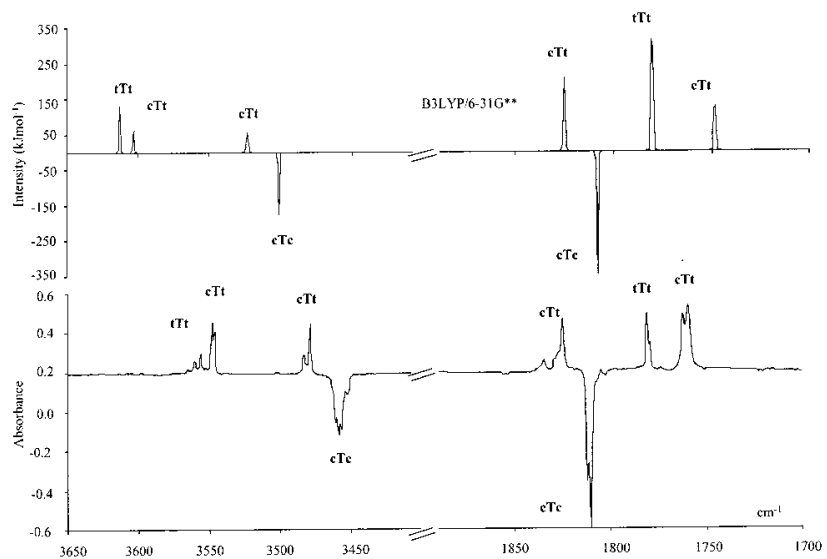

Figure 3. Calculated and observed spectra $\left(3650-3400 \mathrm{~cm}^{-1}\right.$ and $1900-1700 \mathrm{~cm}^{-1}$ regions) of oxalic acid isolated in an Ar matrix. Calculated spectra simulate the absolute intensities using Gaussian functions with an arbitrary full width at half-height of $1 \mathrm{~cm}^{-1}$ for the three most stable conformers of oxalic acid. Experimental data correspond to difference spectra $\left(6712 \mathrm{~cm}^{-1}\right.$ irradiated sample nonirradiated sample).

due to the cTt conformer, giving rise to the doublet observed near $1810 \mathrm{~cm}^{-1}$ (see Figures 2 and 3). Finally, the doublet at ca. $1780 \mathrm{~cm}^{-1}$ is ascribable to the IR active carbonyl stretching mode of tTt where the two carboxyl groups are trans and nonintramolecularly hydrogen bonded. The splittings of the bands are probably due to matrix field effects that are rather commonly observed in spectra of matrix-isolated species, especially if the vibrational modes involve large changes in the molecular dipolar moment. ${ }^{3,21}$

In the $\mathrm{OH}$ stretching region, the irradiation at $6712 \mathrm{~cm}^{-1}$ leads to an increase of two triplets at 3565-3555 and 3550-3545 $\mathrm{cm}^{-1}$ that can be ascribed respectively to the IR active $\mathrm{OH}$ stretching modes of the non-hydrogen-bonded hydroxylic groups of tTt and cTt. A doublet at $3485-3480 \mathrm{~cm}^{-1}$ is assigned to the hydrogen-bonded hydroxylic group of the cTt conformer. The $\mathrm{OH}$ stretching fundamental mode of the cTc conformer corresponds to the downward multiplet at $3460-3450 \mathrm{~cm}^{-1}$.

The next irradiation at $6755 \mathrm{~cm}^{-1}$ excites the first overtone of the $\mathrm{OH}$ stretching mode of the cTt conformer (intramolecularly bonded $\mathrm{OH}$ group). This irradiation at $6755 \mathrm{~cm}^{-1}$ followed the first pumping at $6712 \mathrm{~cm}^{-1}$. The observed difference spectrum in the $\mathrm{C}=\mathrm{O}$ and $\mathrm{OH}$ stretching regions together with the calculated spectra are presented in Figure 4. In these spectra, the bands belonging to conformer cTt appear as negative peaks, whereas those belonging to the $\mathbf{c T c}$ and $\mathbf{t T t}$ conformers point upward. Thus, irradiation at this frequency leads to conversion of $\mathbf{c T t}$ to both $\mathbf{c T c}$ and $\mathbf{t T t}$. Once again, the irradiation is shown to be effective in promoting internal rotation about the $\mathrm{C}-\mathrm{O}$ bond. Similarly to the irradiation at $6712 \mathrm{~cm}^{-1}$, no evidence of rotamerization about the $\mathrm{C}-\mathrm{C}$ bond was observed.

The energy differences between the three observed conformers can be estimated on the basis of the experimental IR band intensities recorded immediately after deposition, taking into account the theoretically predicted intensities ${ }^{7}$ and assuming that no conformational isomerization takes place during the deposition process. An energy difference of ca. $10 \mathrm{~kJ} \mathrm{~mol}^{-1}$ between cTt and cTc was obtained by this approach, whereas conformer tTt was estimated to be higher in energy than the conformational ground state by ca. $16 \mathrm{~kJ} \mathrm{~mol}^{-1}$, corresponding to relative populations at the deposition temperature of cTc: $95.9 \%, \mathbf{c T t}$ : $3.6 \%$, and tTt: $0.5 \%$. These results were obtained from the intensities of the $\mathrm{O}-\mathrm{H}$ or $\mathrm{C}=\mathrm{O}$ stretching modes by weighting the experimental integrated intensities by the corresponding

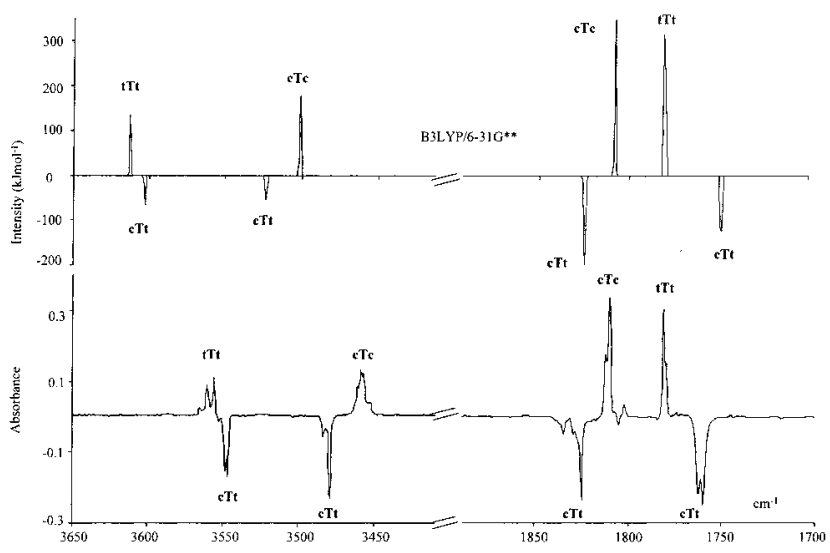

Figure 4. Calculated and observed spectra $\left(3650-3400 \mathrm{~cm}^{-1}\right.$ and $1900-1700 \mathrm{~cm}^{-1}$ regions) of oxalic acid isolated in an Ar matrix. Calculated spectra simulate the absolute intensities using Gaussian functions with an arbitrary full width at half-height of $1 \mathrm{~cm}^{-1}$ for the three most stable conformers of oxalic acid. Experimental data correspond to difference spectra $\left(6755 \mathrm{~cm}^{-1}\right.$ irradiated sample -6712 $\mathrm{cm}^{-1}$ irradiated sample).

calculated IR absorption cross-sections. It is worth mentioning that the DFT calculated values are 10.11 and $15.17 \mathrm{~kJ} \mathrm{~mol}^{-1}$, respectively, corresponding to relative populations at $373 \mathrm{~K}$ of cTc: 95.15 , cTt: 3.64 , and tTt: $0.71^{7}$, thus being in very good agreement with the observed data.

After irradiation at $6755 \mathrm{~cm}^{-1}$ during $10 \mathrm{~min}$, ca. $46 \%$ of the population of cTt was converted into cTc $(27 \%)$ and $\mathbf{t T t}$ $(19 \%)$ while taking into account the calculated IR absorption cross-sections. This result is in qualitative agreement with the relative order of magnitude of the calculated energy barriers associated with the $\mathbf{c} \mathbf{T t} \rightarrow \mathbf{c T c}$ and $\mathbf{c T t} \rightarrow \mathbf{t T t}$ isomerization processes, the first being $2.9 \mathrm{~kJ} \mathrm{~mol}^{-1}$ lower than the last. ${ }^{7} \mathrm{On}$ the other hand, $\mathbf{c T c} \rightarrow \mathbf{c T t}$ isomerization was found to be considerably more efficient than $\mathbf{c T c} \rightarrow \mathbf{t T t}$ when irradiation at $6712 \mathrm{~cm}^{-1}$ was undertaken, as can be expected because $\mathbf{c T c} \rightarrow \mathbf{t T t}$ involves the breaking of two hydrogen bonds instead of one hydrogen bond as in $\mathbf{c T c} \rightarrow \mathbf{c T t}$.

Selective irradiation of the $\mathrm{OH}$ stretching vibrations have been found to be of great utility to study conformational isomerization processes in carboxylic compounds. ${ }^{10-12}$ Nevertheless, it should be emphasized that the elementary mechanism of IR-induced rotamerization is far from being completely understood. For instance, direct coupling of the excited overtone levels with the torsional manifold is a very high-order process, thus quite improbable. The role of the solid host in intramolecular energy transfer is not clear either.

As mentioned earlier, observation of other conformers $(\mathbf{t C t}$ and $\mathbf{c C t}$ ) in the nonirradiated matrix was not expected, taking into consideration their predicted relative populations. Indeed, the estimated $\mathbf{c C t}$ population in the gas at the deposition temperature $(373 \mathrm{~K})$ is lower than $0.1 \%{ }^{7}$ For tCt, though instantaneous cooling of the $373 \mathrm{~K}$ gas would lead to a population of ca. $0.5 \%$ as estimated on the basis of the DFT calculations, ${ }^{7}$ the population in the matrix can be expected to be much smaller, because fast conversion of this form to tTt during sample deposition may easily occur, considering the very low energy barrier separating these two forms (ca. $1.6 \mathrm{~kJ}$ $\mathrm{mol}^{-18}$ ).

Another relevant observation obtained in the irradiation experiments is the fact that no evidence was found of any photochemically induced isomer with a cis $\mathrm{O}=\mathrm{C}-\mathrm{C}=\mathrm{O}$ axis. In fact, taking into consideration the theoretically calculated energy barriers associated with conformational interconversion, 
TABLE 2: Observed and Scaled ${ }^{a}$ B3LYP/6-31G** Frequencies of Three Most Stable Oxalic Acid Conformers Isolated in an Argon Matrix

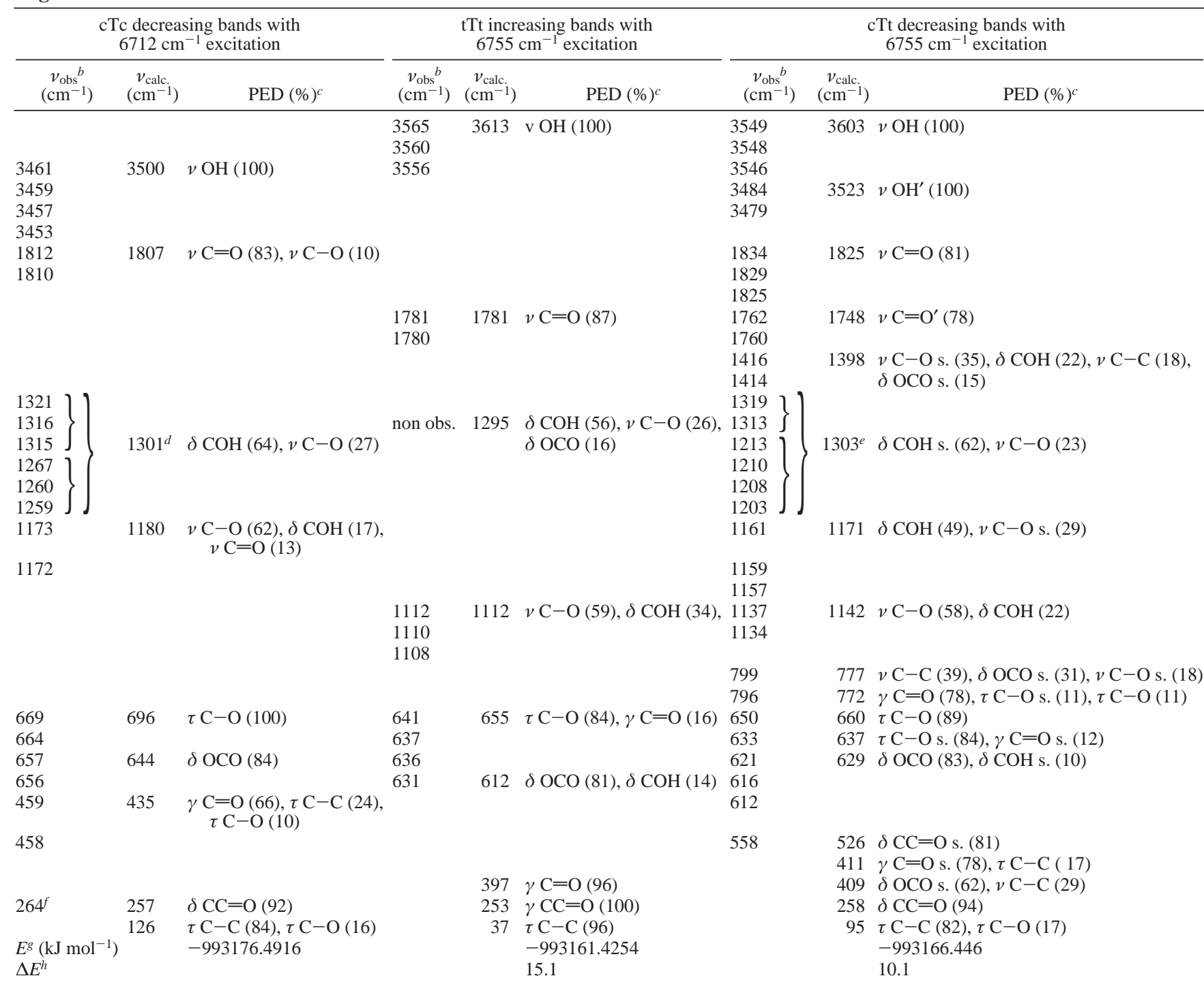

${ }^{a}$ Scale factor $0.9614 .{ }^{b}$ Minor bands not listed, attributed to nonfundamental modes, were observed at: 1855, 1853, 1483, 1481, 1290, 1286, 1284, 1153, 1129, 1127, 1103, 1100, 1098, 996, 994, 990 (cTc); 1187 (tTt), and 1459, 1449, 1062, 1060, 1057, 824 (cTt). ${ }^{c}$ Only contributions higher than $10 \%$ are listed. ${ }^{d}$ Fermi resonance of $\delta \mathrm{COH}$ with $\left[\tau \mathrm{C}-\mathrm{O}\left(B_{g}\right)+\gamma \mathrm{C}=\mathrm{O}\left(A_{u}\right)\right]$; ${ }^{e}$ Fermi resonance of $\delta \mathrm{COH}$ with $2 \delta \mathrm{OCO} .{ }^{f}$ Taken from ref 5. ${ }^{g}$ B3LYP/6-31G** energy. ${ }^{h}$ B $3 \mathrm{LYP} / 6-31 \mathrm{G}^{* *}$ energy compared with the most stable conformer. $\nu$, stretching; $\delta$, bending; $\tau$, torsion; $\gamma$, rocking.

one can expect both $\mathbf{c t}$ and $\mathbf{t} \mathbf{C t}$ to be found. Conformer $\mathbf{c} \mathbf{C t}$ might be obtained from cTt because the calculated $\mathbf{c T t} \rightarrow \mathbf{c C t}$ rotational barrier is estimated to be $4.62 \mathrm{~kJ} \mathrm{~mol}^{-1}$ lower than that associated with the observed $\mathbf{c} \mathbf{T t} \rightarrow \mathbf{t T t}$ process. ${ }^{7}$ Conversion into $\mathbf{t C t}$ form is possible via more complex pathways involving either $\mathbf{c C t}$ or $\mathbf{t T t}$ as intermediates. Nevertheless, despite the energy transferred to the molecules during the irradiation being ca. $80 \mathrm{~kJ} \mathrm{~mol}^{-1}$, that is, above the calculated energy barriers (the highest calculated energy barrier for these processes is $<75$ $\mathrm{kJ} \mathrm{mol}^{-17}$ ), the internal rotation around the $\mathrm{C}-\mathrm{C}$ bond does not take place. A possible explanation for this finding requires consideration of volume restrictions to the internal rotation imposed by the matrix. Internal rotation about the $\mathrm{C}-\mathrm{C}$ bond involves the motion of heavy atoms within the noble gas cage, which requires significant reorganization of the matrix. Consequently, the effective energy barriers for $\mathrm{C}-\mathrm{C}$ internal rotation in the matrix-isolated molecules may be considerably higher than for the molecule in a vacuum, thus preventing the reaction to occur. Note that the observed interconversion processes involve only motion of hydrogen atoms and do not require any major matrix rearrangement.
Assignment of IR Spectra of cTc, cTt, and tTt Conformers. Because the IR-irradiation experiments enabled the clear discrimination of the bands of the three observed conformers (see Figures 2-4), the complete assignment of the vibrational signature of these conformers could be undertaken. In Table 2 we present the experimental and calculated wave numbers and the potential energy distribution for the conformational ground state (cTc) and conformers cTt and tTt, respectively. The symmetry coordinates used to perform the normal coordinate analysis are shown in Table 1.

The assignments here made for the lowest-energy conformer follow closely those reported in ref 3 . The two observed complex bands at ca. $1260-1270 \mathrm{~cm}^{-1}$ and $1315-1320 \mathrm{~cm}^{-1}$ are ascribed to a Fermi resonance doublet (split because of matrix site effects) resulting from interaction between the fundamental $\delta \mathrm{COH}\left(B_{u}\right)$ vibration and the $\tau \mathrm{C}-\mathrm{O} \mathrm{s} .+\gamma \mathrm{C}=\mathrm{O}\left(B_{g} \times A_{u}=\right.$ $B_{u}$ ) combination band.

In the case of conformer cTt, some of the assignments of ref 3 are now revised. In particular, the $\mathrm{C}-\mathrm{O}$ s. stretching and the $\delta \mathrm{CC}=\mathrm{O}$ s. modes (which were not assigned in ref 3) are now ascribed respectively to the doublet appearing at 1415/1416 
$\mathrm{cm}^{-1}$ and to the band at $558 \mathrm{~cm}^{-1}$, whereas the two $\delta \mathrm{COH}$ in-plane bending vibrations are now assigned to the doublet at $1161 / 1157 \mathrm{~cm}^{-1}(\delta \mathrm{COH}$; see Table 2$)$ and to the Fermi resonance doublet (split because of matrix site effects) whose component bands appear at 1319/1313 $\mathrm{cm}^{-1}$ and $1213-1203$ $\mathrm{cm}^{-1}(\delta \mathrm{COH}$ s. interacting with the first overtone of $\delta \mathrm{O}=\mathrm{C}-$ $\mathrm{O})$.

The assignments made for the tTt conformer observed now for the first time are straightforward. As for the other observed forms, the calculated and experimental data for this form are in excellent agreement. It is worth mentioning that we did not observe clearly a band ascribable to the $\delta \mathrm{COH}$ mode of this conformer because this vibration is predicted to occur near the very intense and structured band due to the most stable conformer at $1267-1259 \mathrm{~cm}^{-1}$ (calculated frequency for $\delta \mathrm{COH}$ in tTt: $1295 \mathrm{~cm}^{-1}$; see Table 2).

It is also interesting to point out that the difference of about $70 \mathrm{~cm}^{-1}$ between the observed frequencies associated with the free (3549-3546 $\mathrm{cm}^{-1}$ ) and hydrogen-bonded (3484-3479 $\mathrm{cm}^{-1}$ ) $\mathrm{O}-\mathrm{H}$ group in conformer cTt indicates that in oxalic acid the intramolecular hydrogen bond is weaker than in glycolic acid $\left(80 \mathrm{~cm}^{-1}\right)^{22}$ or in water dimer $\left(106 \mathrm{~cm}^{-1}\right)^{23}$

\section{Conclusion}

Using narrowband tunable irradiation in the $6800-6700 \mathrm{~cm}^{-1}$ region, it was possible to unequivocally identify the three lowestenergy conformers of oxalic acid monomer and perform a complete vibrational assignment of their IR spectra in an argon matrix at $7.5 \mathrm{~K}$. In consonance with the previous studies, the most stable conformer was found to be the cTc conformer, which is characterized by two $\mathrm{OH} \cdots \mathrm{O}=$ intramolecular hydrogen bonds, and the second most stable conformer (cTt) exhibits a single intramolecular hydrogen bond. The third most stable conformer was observed experimentally for the first time and found to be the tTt conformer, with the two carboxyl groups being in a trans configuration and having no intramolecular hydrogen bonds. All observed conformers exhibit a trans structure around the central $\mathrm{C}-\mathrm{C}$ bond.

The selective IR pumping promotes conformational interconversion between the three observed conformers (which implies internal rotation around a $\mathrm{C}-\mathrm{O}$ bond). On the other hand, $\mathrm{C}-\mathrm{C}$ internal rotation leading to conformers exhibiting a cis $\mathrm{O}=\mathrm{C}-\mathrm{C}=\mathrm{O}$ axis was not observed, which can be explained taking into consideration volume restrictions imposed by the rigidity of the matrix that increases the effective barrier for the rotation around this bond. The same behavior has been observed in other dicarboxylic acids that are actually being studied in our laboratories (e.g., malonic acid, fumaric acid).

Acknowledgment. This work has been held within the PRAXIS XXI (QUI/2/2.1/412/94) research program that is also partially funded by FEDER. The financial support of Academy of Finland is also acknowledged.

\section{References and Notes} 2242

(1) Derissen, J. L.; Smit, P. H. Acta Crystallogr. B. 1974, B30, 2240-

(2) Maçôas, E. M. S. Caracterização Estrutural e Espectroscópica de Ácidos Carboxílicos; Department of Chemistry, University of Coimbra, Portugal, Internal Report, 1997 (and references therein).

(3) Nieminen, J.; Räsänen, M.; Murto, J. J. Phys. Chem. 1992, 96 , $5303-5308$.

(4) Stace, B. C.; Oralratmanee, B. C. J. Mol. Struct. 1973, 18, 339.

(5) Redington, L. R.; Redington, T. E. J. Mol. Struct. 1978, 48, 165

(6) Bock, C. W.; Redington, R. L. J Chem. Phys. 1986, 85, 5391.

(7) Higgins, J.; Zhou, X.; Liu, R.; Huang T. T.-S. J. Phys. Chem. A 1997, 101, 2702-2708

(8) Godfrey, P. D.; Mirabella, M. J.; Brown R. D. J. Phys. Chem. A 2000, 104, 258.

(9) Bock, R. A. Can. J. Chem. 1984, 62, 1414

(10) Kulbida, A.; Nosov, A. J. Mol. Struct. 1992, 265, 17.

(11) Kulbida, A.; Fausto, R. J. Chem. Soc., Faraday Trans. 1993, 89 , 4257.

(12) Pettersson, M.; Lundell, J.; Khriachtchev, L.; Räsänen, M. J. Am. Chem. Soc. 1997, 119, 11715.

(13) Becke, A. D. J. Chem. Phys. 1993, 98, 5648.

(14) (a) Lee, C.; Yang, W.; Parr, R. G. Phys. Rev. 1988, B37, 785. (b) Miehlich, B.; Savin, A.; Stoll, H. Preuss, H. Chem. Phys. Lett. 1989, 157, 200.

(15) Frisch, M. J.; Trucks, G. W.; Schlegel, H. B.; Gill, P. M. W.; Johson, B. G.; Wong, M. W.; Foresman, J. B.; Robb, M. A.; Head-Gordon, M.; Replogle, E. S.; Gomperts, R.; Andres, J. L.; Raghavachari, Binkley, J. S.; Gonzalez, C.; Martin R. L.; Fox, D. J.; Defrees, D. J.; Baker, J.; Stewart, J. J. P.; Pople, J. A. GAUSSIAN92/DFT(rev. G.2), Gaussian Inc., Pittsburgh, PA, 1993.

(16) Hehre, W. J.; Ditchefield, R.; Pople J. A. J. Chem. Phys. 1972, 56, 2257.

(17) Fausto R. TRANSFORMER (version 2.0), Chemistry Department, University of Coimbra, Portugal, 1997.

(18) Faria, M. D. G.; Fausto R. BUILD-G (version 2.0) and VIBRAT (version 2.0). Chemistry Department, University of Coimbra, Portugal, 1997 (these programs incorporate several routines from programs GMAT and FPERT, Fuher, H.; Kartha, V. B.; Krueger, P. J.; Mantsch, H. H. N. R. C. C. Bull. 1976, 15, 1.

(19) Teixeira-Dias, J. J. C.; Fausto, R. THEOCHEM 1993, 282, 123

(20) Fausto, R. THEOCHEM 1994, 315, 123.

(21) Hallamasek, D.; Babka, E.; Knözinger, E. J. Mol. Struct. 1997, 408/409, 125.

(22) Redington, R. L.; Liang, C. K. J. Mol. Spectrosc. 1984, 104, 25.

(23) Fröchtenicht, B.; Kaloudis, M.; Koch, M.; Huisken, F. J. Chem. Phys. 1996, 105, 6128 